\title{
On Hungarian Philosophy. Its European Past and European Future
}

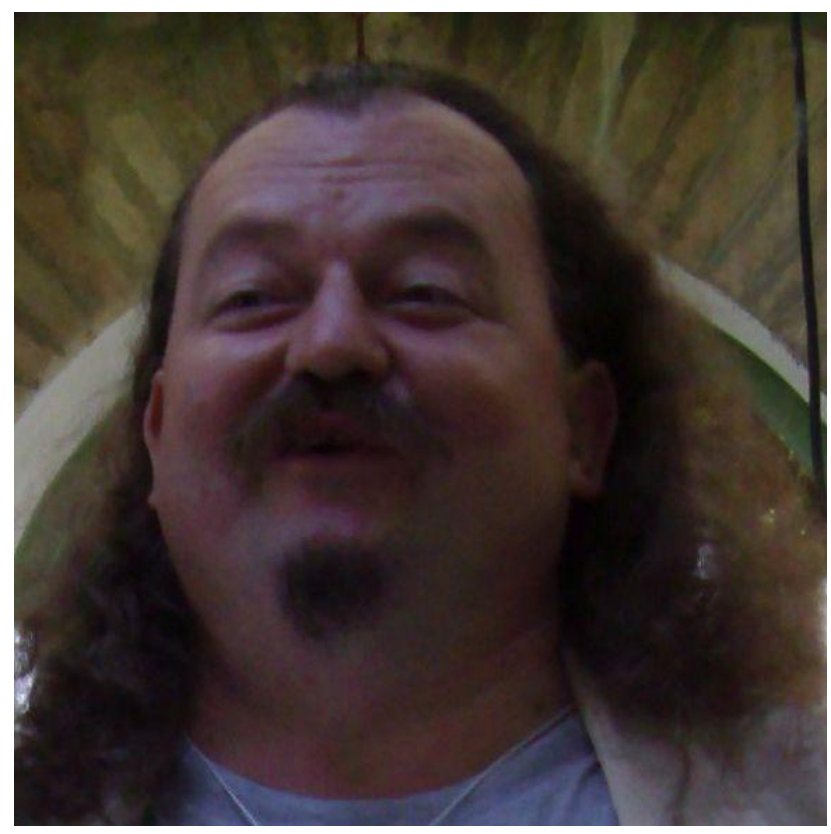

Béla Mester (1962), PhD, Senior Research Fellow of the Institute of Philosophy, Research Centre for the Humanities, Hungarian Academy of Sciences, Budapest, Hungary; share-time associate professor of University of Nyíregyháza when he is an alumnus; member of the editorial boards of Hungarian Philosophical Review and Kellék; vice-president of the Hungarian Philosophical Society; Doctor universitatis of history of philosophy (ELTE University, Budapest, 1997); PhD of literary studies (UBB University, Cluj/Kolozsvár/Klausenburg, 2003, in Romania, in Hungarian); $\mathrm{PhD}$ of political philosophy (ELTE University, Budapest, 2005); fields of research: history of early modern political philosophy, history of Hungarian philosophy.

Tudor Petcu: At the beginning of our dialogue I wish to make reference to the meaning of Hungarian philosophy in the context of European philosophy. I mean I think it would be necessary to present in a relevant way the role that the Hungarian philosophy has played in the evolution of the European philosophy, especially western philosophy. So, what could you say about this topic?

Béla Mester: I can answer as a historian of philosophy who is focussed on the actual research project managed by him as a principal investigator entitled Narratives of Hungarian Philosophy 1792-1947 (from the Kantian debates in Hungarian philosophy to the prohibition of the academic periodical, entitled Athenaeum). Because of my intellectual background, and my field of research, all of my answers will be formulated from the point of view of an historian of the Hungarian philosophy, by other words, with a bias of a historian of philosophy.

Your question refers to one of the fundamental problems of every nation-level historiography of philosophy, amongst them the ones of the greatest philosophical cultures of Europe. It is always a crucial question to find a well-founded link between the universality of philosophy, the role of philosophy in a national culture, and the role of the philosophical tradition of a nation in the universal (European) philosophy. In the self-reflection of the Hungarian philosophy, János Erdélyi's Philosophy in Hungary (1865-1866) has formulated a classical solution. In his great Hegelian vision of history of philosophy, the Hungarian story is a long march from the unconscious philosophical elements hidden in the structure of the Hungarian language (thesis) through the 
cultivation of the mainstream philosophies of the actual epoch in Latin (antithesis) till the happy end, when the Hungarian philosophy and its terminology in its native language is in harmony with the top (and end) of the universal philosophy that is Hegelianism (synthesis). Albeit, Erdélyi's vision cannot be continued in the historiography, it has an inevitable hidden influence on the opinions on the connections between philosophy and national culture. In general, a relatively small national philosophical culture like the Hungarian one has three strategies to find its position in the universal scene. We can try finding several star-philosophers in the past or in the present and using them as a wild card for the tournament of philosophy in international level. This method can work on the surface; I can identify Hungarian philosophy with the works of György (Georg) Lukács or with the theory of personal knowledge of Mihály (Michael) Polányi or with the philosophy of science of Imre Lakatos, etc. They are important names in the Hungarian tradition and known authors for the international audience of philosophy. I think it is an inevitable step for the selfunderstanding of the Hungarian philosophy, but it is not enough without offering a complete narrative of the history of the Hungarian philosophical traditions. Another way is to develop a detailed, philologically sophisticated history of the local receptions of the mainstream philosophies. It is not too easy and you cannot find a sensational result. If you are the best in this genre, at the end you can write a chapter about the Hungarian, Romanian, etc. reception of Hume or Locke in a Cambridge volume on the Continental reception of British philosophers. At the first glance it is a highly boring field of research, but very important. If you look at the greatest manuals of an epoch of history of philosophy, usually you can find that there is no information about East-CentralEurope, or there are just general phrases without concrete data. (Recently you can see this phenomenon in Jonathan Israel's monograph on Radical Enlightenment.) Authors of these manuals are not guilty, they use the data offered by the historians of philosophy of our region; it is our task to modify the position of our region in the map of universal philosophy. However, the research programs of history of reception are needed and important elements of the self-reflection of the Hungarian philosophy; it is not enough alone; and it is counter-productive in several cases. The most interesting stories are based on the reception of different trends; sometimes they did not communicate with each other, both of them were visible from a Hungarian (or other CentralEuropean) perspective, only. It would be fruitful a coordinated research-program to investigate the common philosophical patterns of our region from a comparative perspective.

Tudor Petcu: Which are the main philosophical approaches assumed over the years in the different academic milieus in Hungary? Can we talk about a strong Hungarian phenomenology, or about any analytical Hungarian philosophy, or so? Every country where philosophy was assumed as a field of research has had a specific and general philosophical tradition, as for example England, very wellknown through its analytical philosophy, or Germany through its idealism or phenomenology expressed by Edmund Husserl or Martin Heidegger. In this case, what about the philosophical tradition in Hungary?

Béla Mester: I think we should be careful with the concept of "national spirit" of philosophical trends. However, we can feel the differences of the philosophical climate of the national cultures of Europe; we should not forget that they are constructions of historiographies of philosophy embedded in different national cultures. However, Descartes and Leibniz were French and German persons, they did not identify themselves as French or German philosophers; nationalisation of their philosophies is a product of the centuries after their lifetime. This constructed and historical feature of the concept of the national character of philosophy is the clearest in the Hungarian case when the first program to make "Hungarian philosophy" (1830) was identical with the program to formulate a national narrative of the philosophical heritage of Hungary.

Nowadays, boundaries of a philosophical part of a national culture have become more malleable than they were ever, both from the points of view of the linguistic and geographical boundaries. 
Hungarian philosophers in the neighbouring countries (e.g. Romania) are active participants of the philosophical lives of both countries. (A Hungarian philosophical periodical entitled Kellék is registered both in Romania, and in Hungary; another Hungarian philosophical periodical in Transylvania, entitled Többlet has a series of special issues for the presentation of the PhD-schools of Hungary, etc.) Hungarian philosophers of West Europe, and of the world, amongst them ancient emigrants, can participate in the Hungarian daily philosophical life. A new phenomenon in Hungarian culture is the presence of the Central European University (CEU). However, it is an international institution with international faculty members, established by the laws of New York State; it has become an integrated part of Hungarian cultural life. Its philosophical department was one of the best tens in Europe by a recent independent evaluation.

Concerning the present trends of Hungarian philosophy we should mention at first the name of László Tengelyi, a great figure of the international scholar community in the field of phenomenology. He died in the last year, just after the conference by the opportunity of his $60^{\text {th }}$ birthday. However, he has spent his last years as a German professor in Wuppertal, he has always remained an important figure of the community of Hungarian philosophers; he was an active member of the advisory board of the Hungarian Philosophical Review, he has regularly participated in Hungarian conferences, and had publications in Hungarian. His figure mirrors the importance and quality of (German- and French-style) phenomenology in the contemporary Hungarian philosophical life.

Its counterpart is a significant Hungarian tradition of logic, based on our old tradition of mathematics. After its "war of independence" against the "dialectical logic" of the official Marxism, it has achieved an estimated position within the Hungarian philosophical life. The international significance of this discipline is mirrored in the long and multi-coloured list of authors of the special issue of Hungarian Philosophical Review in English in memoriam Imre Ruzsa, the father of the modern Hungarian logics (2010). School of logic of our philosophical life has been connected with both the intellectual workshops of philosophy of science, and with the analytical philosophy. The former one is a relatively old tradition in Hungarian philosophy, the last one has appeared relatively later than in the neighbouring philosophical cultures. (It is a strange fact of the history of philosophy that the Vienna Circle has just a single member of Hungarian origin, and has almost zero influence on Hungary in the time when the cultural connections between Vienna and Budapest were vivid in other cultural fields.) In the last years, it was one of the most significant events of our philosophical life an open debate between the protagonists of the analytical and phenomenological traditions about the concept and meaning of philosophy. (Several years ago it was my task to edit a Hungarian special issue of the periodical entitled Filozofia of the Slovakian Academy of Sciences, as a twin of the special Slovakian issue of Hungarian Philosophical Review. By my conception as an editor, a report on this debate has represented our everyday scholar activities in a nutshell, for the Slovakian audience.) Philosophy of language has an important position; it is a field of research what is important both for analytical and phenomenological traditions, and for the logicians, as well.

Historical point of view was always important in Hungarian philosophical tradition. Within this scholar community, Hungarian researches of the history of antiquity had traditionally estimated position in the international scene. Researches of early modernity, and Kantianism had always a distinguished importance in Hungarian philosophy, partly because of the role of the Cartesian and Kantian tradition in the history of Hungarian philosophy. A Hungarian speciality is the philosophical orientation of a branch of Hungarian sinology. This intellectual workshop has always genuine theories in the field of the interpretation of the history of Chinese thought; their last achievement is a new history of Chinese philosophy based on the traditions of Hungarian sinology, 
with an interesting analysis from the point of view of the (European-Chinese) comparative history of philosophy.

Political philosophy and philosophy of law in Hungary, called "the country of lawyers", has always a distinguished role in Hungarian philosophy, after the collapse of Communism had a relatively dominant position in the public sphere.

Aesthetics has a continuous tradition from the end of the $18^{\text {th }}$ century, and it has significant intellectual workshops nowadays, as well. There is an actual research project for writing its history from its beginning, written in Latin till our age.

Tudor Petcu: Western philosophy has always accorded a huge attention to the relation between philosophy and theology although there is basically difficult to find too many common denominators, first of all because of their comprehensive logics. Of course, from this point of view there would be a lot to say, especially if we would need to take into account the modal logics as a way to explain the Reality in comparison with theology mostly based on a mystical worldview which has its own logics. But we shouldn't forget about the different Christian efforts in the Middle Age to create a liaison, a strong connection between philosophy and theology, as Saint Anselm or Thomas Aquinas did. Anyway, what can you say about the way by which was defined the relation between philosophy and theology in Hungary and who were the main Hungarian philosophers focused on the analyses of this topic?

Béla Mester: In Hungarian philosophy, amongst the philosophers with Catholic identity, there has always been a significant neo-Thomist tradition from the end of the $19^{\text {th }}$ century till nowadays. As a field of research, philosophy of religion has traditionally strong positions, especially from a historical point of view, both in the research centres of the church and state universities, and in our academy of sciences. There is a Catholic intellectual workshop for a new Christian philosophy, and on the other side has emerged a new, modernised atheist argumentation. Despite of these important phenomena, the main characteristics of the relationship of philosophy and religion in Hungarian tradition is mainly rooted in cultural identity of the philosophical authors, not in the question of the relationship between knowledge and faith, or similar classical topics. For example, Hungarian Cartesian movement, and the Cartesian debates of the $17^{\text {th }}$ century has appeared within the Protestant, dominantly Calvinist institutional network. In the same time, a Suarez-style late scholasticism was an exclusive Catholic discipline. Later, however, the Kantian debate (1792-1822) was organised by the new, religiously neutral public sphere of the printed brochures and periodicals, their main protagonists were mainly Protestants on both sides. As late as the age of the neo-Kantian philosophy of values in the end of the $19^{\text {th }}$ century and in the beginning of the $20^{\text {th }}$ century, the most important Hungarian school of this kind of philosophy has not any Catholic members. (It is the circle of Károly Böhm who was born in Banská Bystrica, today in Slovakia, was living for decades in Budapest and died as a professor in Cluj (Kolozsvár, or Klausenburg, in Transylvania) in 1911. Today there is a lecture room called "Sala Böhm Károly" for his memory in UBB University.) In the same time, a young philosopher (Ákos Pauler, an emblematic figure of the interwar period of philosophy in Hungary) with Catholic identity has developed his ethics on different foundations. He has not any Protestant disciples. At the same time, this strong denominational determination is does not work in today Hungarian philosophy, we must calculate with it as an important historical element.

Tudor Petcu: As far as I know, one of the most Hungarian philosophers was Ágnes Heller, who joined the communist party and so she began to develop an interest in Marxism. So, please describe us in some words her philosophical personality, so influenced by the school of the continental philosophy. 
Béla Mester: Ágnes Heller belonged to the circle of the disciples of György Lukács. Albeit, Lukács was a member of the Hungarian Communist emigrant enclave in Moscow, and has come back as an aspirant for the leadership of the cultural life, after the Communist political turn (1948) he has been marginalised in political and cultural life. He and his disciples were always heretics of the Marxism in the eyes of the rulers of the country. In the years before Heller's emigration, she and other members of the same circle were the participants of the movement for creating a Marxist anthropology, and ethics, connected with the existentialism of this epoch. Based on the Hungarian philosophical traditions, all of the members of this circle has founded his or her opinions with serious researches in the topics of history of philosophy, connected their field of interest. (In the case of Heller these historical topics were the Hegelian movement in Hungary, Aristotle's ethics, and the Renaissance ideal of human being.) In the Communist bloc, there were only two relevant intellectual workshops of this movement: Budapest school, and the Praxis Circle in Zagreb. (There were several very important individual authors of this genre in Poland, as well.) They have appeared in the scene of politics with the Korčula petition against the Soviet occupation of Czechoslovakia. (Korčula is a Croatian island when there were usual summer universities in this time, offering a free meeting point for the reform-Marxist philosophers of the Communist bloc.) It is symptomatic that almost all the significant figures of this scene had to emigrate in the seventies both from Poland and Hungary, and the periodical of the Croatian Philosophical Society; entitled Praxis was prohibited in the same time. In the Hungarian case the turning point was the "philosophers' trial" in 1972, just after the death of György Lukács, in accordance with the Conservative turn of the Hungarian Communist politics, against the economic reform (1968), and its possible consequences for the culture and politics. After the trial, the majority of the disciples of Lukács left the country, and the main figures of the second generation of the Budapest school (by the slang of the Hungarian intelligentsia the "Lukács-kindergarden") became inland dissidents in Hungary, without a normal job. However, Ágnes Heller lived in Australia and in the USA; at the same time she remained the follower of the Continental tradition. In her new works written in America, and after the collapse of Communism, again in Hungary, from her earlier period remained an interest in the ethical and anthropological problematics. In the time of her emigration the biggest influence on her was the intellectual climate of the New School in New York. In here she was the heir of the position of Hannah Arendt. New School itself has been established by European (mainly German) emigrants, as well. The intellectual positions of Arendt and Heller had important similarities; they were refugees of different totalitarian regimes, and followers of European Continental philosophical traditions in America. Arendt's totalitarianism-book has a special importance for the Hungarians, because of its additional chapter about the revolution of 1956 omitted from some editions. Both the anti-totalitarian political philosophy of Arendt and her model as a public intellectual have been deep influence on Ágnes Heller; it is an important addition for the interpretation of Heller's later works.

Tudor Petcu: We shouldn't forget to highlight the contemporary philosophical theories in Hungary, because in our days it's very hard to find a philosophical task given the technological revolution and the development of pragmatism. I am saying that because the general question that is addressed even in the British and American schools of philosophy is the following: what role can play philosophy in our days, in a society where science is evolving on and on? But in spite of this fact and according to the question I have mentioned above, there are numerous contemporary philosophical views related especially to politics, science and economics. So, which are the most important contemporary Hungarian philosophical theories and approaches?

Béla Mester: I should speak first of all about the institutional embedment of philosophy in Hungary in the Communist era, after its collapse, and today. The Communist political turn after the WWII has destroyed the institutions of philosophy. There were three years without any academic periodical of philosophy, later, a few volumes of Philosophical Yearbook was the only terrain for 
the publications. Philosophical studies were possible in an institute directly controlled by the Communist party, only, in the Stalinist era. In Kádár's Hungary, the situation seemingly has been normalised; an academic periodical has been (re)founded, and philosophy became an integral part of the higher education. The price of this normalisation was a highly restricted position of philosophy in higher education and in intellectual life; (emission of MAs of philosophy was the privilege of the ELTE University in Budapest, in every second year, not for too many students). After the collapse of communism, Hungarian philosophy as an institutional system and as a scholar community has been reconstructed, soon. Hungarian Philosophical Society has been (re)established in the last years of Communism, amongst the other early endeavours of the reestablishment of the civil society; new philosophical intellectual workshops, periodicals, educational programs, and $\mathrm{PhD}$ schools have been established in every significant Hungarian university. Emigrants and inland dissidents have appeared in the universities, with their new points of view. Several philosophers of the research institute of the Academy of Sciences who was artificially separated from the university sphere, and from the possibility of to teach the youth has become professors in the universities. In this situation, philosophy has achieved relatively better positions in public sphere; several philosophers assumed the role of the public intellectual in the media (e.g. Ágnes Heller). In spite of the presence of philosophy in public sphere, it remained a kind of elitism in the behaviour of our scholar community. It was partly a reaction to the ideological-political usage of philosophy, struggle for the autonomy of philosophy as an academic discipline. (There were similar reactions amongst the scholars of literary studies, against the social determination of literature, formulated by Marxism, and for the autonomy of artworks.) A consequence of his (partly hidden) elitism is that applied forms of philosophy, e.g. applied ethics have relatively smaller role in Hungarian philosophy that in other countries in our region.

Nowadays, the institutional background in the education has restricted again. Philosophy is a part of the curricula of just a few secondary grammar schools, and the right of the teachers of philosophy for teaching ethics is continuously contested by the authorities. Programs of philosophy and $\mathrm{PhD}$ schools are in a dangerous situation in almost every university. A new tone of the language of Hungarian politics, which has turned gradually to an anti-intellectual, pseudo-plebeian rhetoric, does not offer a good chance for try a significant role of philosophy in the public affairs. Under conditions of an anti-intellectual political language, and an elitist philosophical self-identity, there are two types of the reflections to the modern world.

The first one is trying to understand our scientist modern world. Hungarian tradition of philosophy of science can offer relevant answers for scientist worldview, by the philosophical analysis of the keywords of different disciplines, which are not, reflected ones within the framework of these disciplines. In the last years were important philosophical discussions e.g. about the meaning(s) of the (different) concept(s) of the evolution, on the possibility of the demarcation between artificial and human minds, etc.

Another way is a kind of a well-established philosophical critique of several phenomena by the disciplines like bioethics, ecological philosophy, and so on. Albeit, these applied philosophies have not enough strong positions in the academic sphere of philosophy, they have a significant laic audience in the circles around several cultural periodicals, and in the sphere of the Hungarian branch of the international movement of philosophical cafés.

Maybe, this scene will be the basis of the reestablishment of Hungarian philosophical tradition. We must remember that in the 1880s, Philosophical Circle of Budapest (ancestor of Hungarian Philosophical Society, established in 1901) was the initiator of the reform of the social embedment of the Hungarian philosophy, out of the academic sphere, as a part of the vivid cultural life of the Budapest cafés. 